\title{
Variation in ant-mediated seed dispersal along elevation gradients
}

\author{
Israel Del Toro ${ }^{\text {Corresp., }}{ }^{1}$, Relena R Ribbons ${ }^{1}$ \\ ${ }^{1}$ Biology Department, Lawrence University, Appleton, Wisconsin, United States \\ Corresponding Author: Israel Del Toro \\ Email address: israedt@gmail.com
}

Ant-mediated seed dispersal, also known as myrmecochory, is a widespread and important mutualism that structures both plant and ant communities. However, the extent to which ant functional types (e.g. granivorous generalists vs. myrmecochorous ants) across environmental gradients affect seed removal rates is not fully understood. We used a replicated, standardized seed removal experiment along elevation gradients in four mountain ranges in the southwestern United States to test predictions that: (1) seed removal rates would be greater at lower elevations, and (2) seed species identity influences seed removal rates, (i.e. seeds from their native elevation range would be removed at higher rates than seeds outside of their native elevation range). Both predictions were supported. Seed removal rates were $\sim 25 \%$ higher at lower elevation sites than at higher elevation sites. The low elevation Datura and high elevation Iris were removed at higher rates in their respective native ranges. We attribute observed differences in dispersal rates to changes in ant community composition, functional diversity, and abundance. We also suggest that temperature variation along the elevation gradient may explain these differences in seed removal rates. 
1 Title: Variation in ant-mediated seed dispersal along elevation gradients.

2

3 Authors: Israel Del Toro ${ }^{1 *}$, Relena R. Ribbons ${ }^{1}$

4

5 Affiliations: ${ }^{1}$ Lawrence University, Biology Department, 711 E. Boldt Way, Appleton WI, 6 54911, USA.

7

8 *corresponding author: Israel Del Toro Israel.deltoro@lawrence.edu

9 Israel Del Toro: ORCID: 0000-0002-3901-8713

10 Relena Ribbons ORCID: 0000-0002-9566-3813

11

12

13

14

15

16

17

18

19

20

21

22

23 


\section{Abstract}

26 Ant-mediated seed dispersal, also known as myrmecochory, is a widespread and important 27 mutualism that structures both plant and ant communities. However, the extent to which ant 28 functional types (e.g. granivorous generalists vs. myrmecochorous ants) across environmental 29 gradients affect seed removal rates is not fully understood. We used a replicated, standardized seed removal experiment along elevation gradients in four mountain ranges in the southwestern United States to test predictions that: (1) seed removal rates would be greater at lower elevations, and (2) seed species identity influences seed removal rates, (i.e. seeds from their native elevation range would be removed at higher rates than seeds outside of their native elevation range). Both predictions were supported. Seed removal rates were $\sim 25 \%$ higher at lower elevation sites than at higher elevation sites. The low elevation Datura and high elevation Iris were removed at higher rates in their respective native ranges. We attribute observed differences in dispersal rates to changes in ant community composition, functional diversity, and abundance. We also suggest that temperature variation along the elevation gradient may explain these differences in seed removal rates. 


\section{Introduction}

48

49

50

51

52

53

54

55

56

57

58

59

60

61

62

63

64

Myrmecochory- ant-mediated seed dispersal - is an ecologically important and

ubiquitous mutualistic interaction that exists between ants and plants (Ness and Bressmer 2005), occurring in over 11,000 species, and across 70 plant families (Lengyel et al. 2010). Seeds of myrmecochorous plants contain lipid-rich appendages called elaiosomes, which serve as nutritional rewards for ants (Warren and Giladi 2014; Gomez and Espadaler 2013, Ness 2005). Variation in seed removal rates can be explained by ant morphological traits (Fokuhl et al. 2012) and seed traits like elaiosome and plant size (Leal et al. 2015; Peters et al. 2003). Ants also influence the dispersal capacity of a seed by making seeds unavailable to other potential seed predators (Leal et al. 2015) and also disperse non-elaiosome bearing seeds through seed harvesting or granivory (Christianini et al. 2007; Taber 1999). In both cases ant-mediated seed dispersal plays a key role in shaping vegetation community structure (Del Toro et al. 2012; Ghobadi et al. 2015), as ants may serve as seed dispersers or predators depending on the context. While ant-mediated seed dispersal or predation plays an important role in vegetation communities, this role likely varies across elevation and habitat gradients. "Sky islands" are individual mountains isolated from larger continuous mountain ranges by vastly different habitat types, in this case the Chihuahuan and Sonoran deserts at the lower elevations. The sky islands of the southwestern United States provide an excellent system for studying how myrmecochory varies along a continuous elevation and habitat gradient. This gradient extends from desert scrub to subalpine coniferous forest (Brusca and Moore 2013), which is an excellent natural experiment as both plant and arthropod communities tend to change systematically along gradients (Andersen 1997, Del Toro 2012). 
Ant-mediated seed dispersal shapes vegetative communities (Rissing 1986) and this

70 important mutualism (or commensalism see Warren et al. 2018) is potentially resilient to

71 increased temperatures in temperate forests in the eastern U.S. (Stuble et al. 2014). However,

72 less is known about the potential breakdown of ant-mediated seed dispersal in a desert to forest

73 mountain gradient. We suspect strong connections between myrmecochorous plants and ants

74 within desert communities (Leal et al. 2015). This could be due to their extreme climates and

75 rapidly changing environmental gradients (for example, intense deluges of rain and dramatic

76 shifts in temperatures in a single day, see Andersen et al. 2015). The intense competition for

77 resources in extreme environments may also mean some ants are reliant on extrafloral nectaries

78 and other plant resources to persist (Aranda-Ricket et al. 2014). Stress for fundamental resources

79 has also led to strengthened ant-plant mutualisms in water-stressed environments (Pringle et al.

80 2013). Thus, we predict that myrmecochory may play a strong role in shaping vegetation

81 communities in desert environments. We also expect tightly coupled ant-plant mutualisms that

82 are species-specific for plants that differ among habitat types and elevations. For example, ant

83 species and plant seed traits that have evolved in the same environment are more likely to be

84 associated with one another, than those that have not.

85 We documented seed removal rates, and the effect of seed species identity on seed

86 removal rates along this gradient. Given previous research at our study locations, we knew ant

87 community composition differed among mountains in the Sky Islands (Andersen 1997), with

88 higher ant abundances observed at lower elevations on the mountains. We predicted that: 1) rates

89 of seed removal would be higher at lower elevations, and 2) individual rates of seed removal for

90 each seed species would be highest at a seeds' native elevation range (the elevation range at

91 which each plant species is endemic, and is observed growing in the wild). 


\section{Materials and Methods}

94 a) Study Site and Organisms

95 We conducted this study on four sky islands in the southwestern United States of 96 America in June and July 2015 (see supporting data file for site details; S1, Table 1). At each

97 elevation band we deployed 10 seed depots, each containing 100 seeds, with 25 seeds from four 98 different plant species (Table 1). To test whether seed removal rates were dependent on species 99 identity, we selected seeds from plants native to different habitats along the elevation gradient.

100 We built seed depots using laminated white index cards covered with an overturned, reinforced, 101 disposable plastic plate (Dixie Co. Atlanta GA, USA) held in place with lawn staples (Easy

102 Gardener Inc. Waco TX, USA) to prevent seeds from being blown by wind or being removed by 103 larger granivores. Ants were allowed to enter and exit the depot through $1 \mathrm{~cm}$ openings, cut out 104 around the covering plate. We counted the remaining seeds every 12 hours over a 48 -hour 105 period. Each depot was deployed and counted within hours of each other, within a single 106 mountain site. We selected seeds from four different plants (Datura, Iris, Oat, and Sumac) to test our 108 second prediction, that seeds would be removed at greater rates in their native elevation range.

109 Datura wrightii is the only species with an elaiosome -bearing seed and is common in desert 110 scrub habitat (typically found at elevations <1800 m.a.s.1.) (Carter 1997). Based on our field 111 observations Datura seeds were typically removed by Harvester ants (Pogonomyrmex spp). Little 112 Leaf Sumac (Rhus microphylla) fruits were observed in the field being harvested by various ant 113 genera (Pogonomyrmex, Aphaenogaster and Pheidole) at mid elevations from 1800 m.a.s.1. to 1142400 m.a.s.1. The Rocky Mountain Iris (Iris missouriensis) normally occurs only in habitat above 
1152400 m.a.s.l. (Brusca \& Moore, 2013), and ants in the genera Formica and Myrmica were

116 observed actively removing seeds from the plants. We harvested seeds from Datura, Iris, and

117 Sumac plants within one week of deploying the experimental seed depots to account for

118 differences in phenological emergence. Lastly, we used an oat seed (Avena sativa) that served as

119 our control group, as it is not native to the study region (thus lacks any eco-evolutionary

120 dynamics with native ant communities) nor does it contain an elaiosome, but may be a source of

121 nutrients for opportunistic and granivorous ants.

122

To assess ant community composition and abundances, we used a16 pitfall trap quadrant

123 array at each sampling location. Pitfall traps were deployed for the same 48 hours when seed

124 removal rates were observed, at each elevation band and site and were directly adjacent with the

125 location of the seed depots. We report ant incidence as the number of pitfalls that captured an

126 individual genus, which is a more conservative metric of ant communities.

\section{7 b) Statistical analyses}

128 We used a generalized linear mixed model (GLMM) to test for an additive (non-

129 interacting predictor variables) effect between elevation and seed species, and to test our first

130 prediction that seed removal would vary across elevation (m.a.s.1.) and site (latitude and

131 longitude coordinates/mountain name). We treated time, elevation, and seed identity as fixed

132 effects, and specified a Poisson distribution for the count data (the number of seeds removed

133 from seed depots). The total number of seeds removed over time was compared among seed

134 species and elevation bands using repeated-measures analysis of variance (RMANOVA). To test

135 our second prediction (that seed identity influences seed removal across elevations) we used a

136 GLMM and Chi square tests for each species separately, and included site as a random factor. 
We conducted an overdispersion test, modified from Ben Bolker (overdisp_fun; see

138 Supplementary material lines 24-32), to test for equal variance in GLMMs given a particular

139 distribution family (Poisson in our case). This function was applied to all glmer models and

140 results are reported in the supplementary materials. Overdispersion was not detected in the global

141 model M1 (which tested all seeds among all elevations and sites), but was present in the

142 individual models of Iris and Sumac. For Iris and Sumac, overdispersed models were fitted using

143 a quasi-Poisson distribution, which allowed us to estimate which sites and elevations are driving

144 the primary detected patterns. For Iris- the significant difference in high elevations is driven by

145 one site, MOG, which indicates there is no overall pattern. For Sumac- variable responses at high

146 elevation sites $(2800 \mathrm{~m})$ may be dampening any possible trends, which indicates there is no

147 overall pattern.

148

149

See the supporting information file (S1) for the detailed code and dataset used in the

150

analyses. All analyses including GLMMs were implemented in R statistical program version

151

3.2.3 (R Development Core Team 2014) using the "lme4" package (Bates et al. 2015) and Chi

152 square tests in the "car" package (Fox and Weisberg 2011). To identify differences in ant

153 community composition we used Principal Component Analysis (PCA) implemented in the

154 "FactoMineR" package and visually inspected PCA biplots.

\section{Results}

Consistent with our first prediction, seed removal rates were higher at low elevations

157 (1600 and $2200 \mathrm{~m}$; Figure 1). Total seed removal rates were similar among sites at $1600 \mathrm{~m}$ and

158 those at $2200 \mathrm{~m}$, but seed removal rates were $23.8 \%$ lower at $2800 \mathrm{~m}$ than at the lower elevations

159 (Figure 1, Figure S1), a pattern consistent with our first prediction. Our repeated measures 
160 analyses suggested a strong additive effect between elevation and seed species (Table $2, \mathrm{p}<$

161 0.001). In all analyses (global model and seed specific models), time influenced the number of

162 seeds removed. This suggests that the longer the depots are active, the more seeds are removed,

163 ranging from $25 \%$ to $58 \%$ over the 48 -hour time period.

164 Datura and Oat seeds accounted for most of the seed removal (Figure 2A, 2C, 13\% and

$16518 \%$ respectively), whereas Iris and Sumac seeds were removed at lower rates $(2 \mathrm{~B}, 2 \mathrm{D}, \sim 5 \%$ for

166 either species). Datura seed removal was highest at the low elevation sites, with no differences

167 between the mid and high elevation sites. Oat seed removal tended to be greater at mid

168 elevations and approximately the same at low and high elevations (Figure 2C), compared to the

169 other seed species. Iris and Sumac seeds were removed less frequently from our depots, with Iris

170 seeds having greater removal rates (Figure 2B) while Sumac had the lowest removal rates

171 between these two species (Figure 2D), at high elevation sites after 48 hours. Our repeated

172 measures analyses suggest that elevation as a constraint on ant and plant communities, was an

173 important factor in explaining seed removal rates for all four species, and site level effects were

174 important for Datura and Oats, but Iris or Sumac.

175 We examined ant communities at the generic level using pitfall trap data and principal

176 components analysis, and found a distinct ant community at high elevations that is characterized

177 by Myrmica and Lasius spp. (Figure 3). We found mid elevation ant communities are

178 characterized by more Tapinoma, Camponotus, Aphaenogaster and Liometopum spp. than either

179 the high or low elevation communities (Figure 3). Low elevation communities are characterized

180 by Dorymyrmex, Crematogaster, Pogonomyrmex, Tetramorium, and Myrmecocystus spp.

181 (Figure 3).

182 Discussion 

environmental gradients, it may be more pronounced in arid low-elevation compared with mesic

185 high-elevation habitats for ant communities. Observed seed removal rates were greater in lower 186 elevations than in higher elevations. Seed removal was strongly dependent on seed species 187 identity and its plant species native elevation range, which was consistent with our predictions.

188 The pattern of total seed removal may be attributable to higher abundance of seed dispersing 189 ants, especially Harvester ants (Pogonomyrmex spp., Novomessor spp.). These two species of 190 harvester ants are more common at lower elevations (Taber, 1998) and have multiple traits which 191 make these ants ideal dispersers of seeds that are dropped while foraging and not consumed 192 (Warren and Giladi 2014; Zelikova et al. 2008), including a specialized dietary preference for 193 seeds (Taber 1999). These harvester ants were observed removing seeds of Datura and Sumac, as 194 well as the control Oat, but never dispersing the Iris. In other temperate region studies, ant abundance is correlated with unimodal species richness and abundance patterns with low ant diversity/abundance at high elevations, with a peak 197 of diversity/abundance in mid to lower elevations (Bharti et al 2013; Lessard et al. 2011). Our 198 results suggest a similar pattern of ant abundance could be driving seed removal rates, as both seed removal and ant abundances were higher at low elevation sites. Myrmecochory may be more prevalent in ecosystems where high ant abundances can be advantageous for dispersing seeds, (e.g. Datura in low-elevations). The mutualistic relationship of harvester ants

202 (Pogonomyrmex) and Datura wrightti has been carefully documented and the effects of Datura 203 seed diets on ant reproductive output have been experimentally tested (Marussich, 2006). Ant 204 community composition also changes along these elevation gradients, with the lower elevations 205 having high abundances of hot-climate specialist and generalized Myrmicinae species, and high 
206 elevation sites tend to have lower abundances of ants which were mainly cold climate specialist

207 and opportunistic species (Andersen 1997) (S1). The observed ant community differences may

208 explain the patterns of seed removal along this gradient. Behaviorally dominant and abundant

209 genera (beyond harvester ants) may remove more seeds at low elevations, while opportunistic

210 genera may remove fewer seeds at high elevation sites. Higher rates of seed removal at lower

211 elevations may also correlate with higher temperatures, which leads to increased ant activity

212 levels (Stuble et al. 2014).

213 Seed species identity also influenced observed seed removal patterns. Datura and Iris

214 seeds were removed at higher rates in their native elevation ranges $(1600 \mathrm{~m}$ and $2800 \mathrm{~m}$,

215 respectively). The pattern detected in our study suggests that at low elevations, ant communities

216 have highly active and abundant, seed-dispersing species (S1). Mid-elevation sites tend to have

217 preferentially granivorous ant communities (as indicated by the higher removal of oat seeds at

218 mid-elevations). High-elevation sites have relatively lower ant abundances (S1) largely

219 comprised of opportunistic species. Our results may reflect an unequal distribution of functional

220 ant diversity along these elevation gradients. This uneven distribution of functional diversity

221 places concern on seed-dispersing ant species that may be sensitive to climate change, especially

222 in temperate (high elevation) ecosystems (Del Toro et al. 2015) or instances where climate-

223 driven ecological mismatches between seed drop and ant activity occur (Warren and Bradford

224 2014).

Future work should explore the specifics of the network of ants interacting with various

226 seed species being dispersed along environmental gradients. For example, by tracking the

227 individual ant species removing individual seeds, we could identify major seed dispersing ant

228 species and the total influence they have on structuring vegetation communities. We recognize 
229 the potential for the influence of seed-drop phenology influencing the seeds being dispersed, a

230 pattern that was documented in eastern North American forests (Warren and Bradford 2014).

231 This may partially explain low rates of Sumac removal, since it tends to drop its seeds earlier in

232 summer than the other seeds (Carter 1997). Given that Datura wrightii is a species of

233 conservation interest and a myrmecoschorous plant with an elaiosome, we also suggest a

234 replicated experiment across a finer resolution elevation gradient would be useful for predicting

235 the fate of Datura in the future.

236

\section{Conclusions}

238 Although myrmecochory is widespread and important in structuring plant and animal 239 communities (Warren and Giladi 2014; Del Toro et al. 2012), this relationship is not equally 240 distributed along elevation and habitat gradients. Furthermore, a single ant species can perform a 241 majority of seed dispersal, such as Pogonomyrmex spp. and Novomessor spp. in this study or 242 Aphaenogaster rudis in the Great Smoky Mountains (Zelikova et al. 2008). We highlight that for 243 some species (Datura and Iris) their ant-mediated dispersal rate is highest in their native

244 elevation range, which may suggest strong mutualistic links between ants and these plant 245 species. The work on seed dispersal along elevation gradients allows us to explore how key ant246 mediated ecosystem processes respond to environmental cues and help us predict how

247 communities might respond to future climatic and habitat change. 
250 We thank Christian Rodriguez and Bill McKay for data collection and genera identification

251 assistance, Sara Baqla and Julie Schlicte for data collection assistance, and the Sanders lab group

252 and Brandon Bestelmeyer for input on previous drafts of this manuscript.

253

254 References:

255 Andersen, A. N. (1997). Functional groups and patterns of organization in North American ant

256 communities: a comparison with Australia. Journal of Biogeography, 24(4), 433-460.

$257 \quad$ http://doi.org/doi:10.1046/j.1365-2699.1997.00137.x

258 Andersen, A. N., Del Toro, I. and Parr, C. L. (2015). Savanna ant species richness is maintained

259 along a bioclimatic gradient of increasing latitude and decreasing rainfall in northern

260 Australia. Journal of Biogeography, 42: 2313-2322. doi:10.1111/jbi.12599

261 Aranda-Rickert, A., Diez, P., \& Marazzi, B. (2014). Extrafloral nectar fuels ant life in

262 deserts. AoB PLANTS, 6, plu068. doi:10.1093/aobpla/plu068

263 Bates, D., Mächler, M., Bolker, B. M., \& Walker, S. C. (2015). Fitting linear mixed-effects

264 models using lme4. Journal of Statistical Software, 67(1), 1-48.

265 http://doi.org/10.18637/jss.v067.i01

266 Bharti, H., Sharma, Y. P., Bharti, M., \& Pfeiffer, M. (2013). Ant species richness, endemicity

267 and functional groups, along an elevational gradient in the himalayas. Asian Myrmecology,

268 5(1), 79-101. http://doi.org/10.1111/j.1600-0706.2010.18772.x 
269 Brusca, R. C., \& Moore, W. (2013). A natural history of the Santa Catalina Mountains, Arizona, 270 with an introduction to the Madrean sky islands. Arizona-Sonora Desert Museum Press.

271 Carter, J. L., Dennis, B., Leggitt, M. C., \& Underwood, W. J. (1997). Trees and shrubs of New 272 Mexico. Mimbres Pub.

273 Christianini, A. V., Mayh, J., Oliveira, P. S., Mayhé-Nunes, A. J., Oliveira, P. S., Mayh, J.,

274

275

276

277

278

279

280

281

282

283

284

285

286

Mayhé-Nunes, A. J. (2007). The role of ants in the removal of non-myrmecochorous diaspores and seed germination in a neotropical savanna. Journal of Tropical Ecology, 23(3), 343. http://doi.org/10.1017/S0266467407004087

Del Toro, I., Ribbons, R. R., \& Pelini, S. L. (2012). The little things that run the world revisited: A review of ant-mediated ecosystem services and disservices (Hymenoptera: Formicidae). Myrmecological News.

Del Toro, I., Silva, R. R., \& Ellison, A. M. (2015). Predicted impacts of climatic change on ant functional diversity and distributions in eastern North American forests. Diversity and Distributions, 21(7), 781-791. http://doi.org/10.1111/ddi.12331

Fokuhl, G., Heinze, J., \& Poschlod, P. (2012). Myrmecochory by small ants - Beneficial effects through elaiosome nutrition and seed dispersal. Acta Oecologica, 38, 71-76. http://doi.org/10.1016/j.actao.2011.09.007

Fox, J., \& Weisberg, S. (2011). An R Companion to Applied Regression, Second Edition. Sage

Ghobadi, M., Agosti, D., Mahdavi, M., \& Jouri, M. H. (2015). Effects of Harvester Ants' Nest Activity (Messor spp.) on Structure and Function of Plant Community in a Steppe 

283.

291

292

293

294

295

296

297

298

299

300

301

302

303

304

305

306

307

308

Gómez, C., \& Espadaler, X. (2013). An update of the world survey of myrmecochorous dispersal distances. Ecography, 36(11), 1193-1201. http://doi.org/10.1111/j.1600-0587.2013.00289.x

Leal, I. R., Leal, L. C., \& Andersen, A. N. (2015). The benefits of myrmecochory: A matter of stature. Biotropica, 47(3), 281-285. http://doi.org/10.1111/btp.12213

Lengyel, S., Gove, A. D., Latimer, A. M., Majer, J. D., \& Dunn, R. R. (2010). Convergent evolution of seed dispersal by ants, and phylogeny and biogeography in flowering plants: A global survey. Perspectives in Plant Ecology, Evolution and Systematics. http://doi.org/10.1016/j.ppees.2009.08.001

Lessard, J.-P., Sackett, T. E., Reynolds, W. N., Fowler, D. A., \& Sanders, N. J. (2011). Determinants of the detrital arthropod community structure: the effects of temperature and resources along an environmental gradient. Oikos, 120(3), 333-343. http://doi.org/10.1111/j.1600-0706.2010.18772.x

Marussic, W.A. (2006). Testing myrmecochory from the ant's perspective: The effects of Datura wrightii and D. discolor on queen survival and brood production in Pogonomyrmex californicus. Insectes Sociaux 53(4), 403-411.

Ness, J. H., \& Bressmer, K. (2005). Abiotic influences on the behaviour of rodents, ants, and plants affect an ant-seed mutualism. Ecoscience, 12(1), 76-81. http://doi.org/10.2980/11195$6860-12-1-76.1$ 
309 Peters, M., Oberrath, R., \& Bohning-Gaese, K. (2003). Seed dispersal by ants: are seed

310 preferences influenced by foraging strategies or historical constraints? Flora, 198(6), 413-

311 420. http://doi.org/10.1078/0367-2530-1210114

312 Pringle E.G., Akçay E., Raab T.K., Dirzo R., Gordon D.M. (2013). Water Stress Strengthens

313 Mutualism Among Ants, Trees, and Scale Insects. PLOS Biology 11(11):

314 e1001705.https://doi.org/10.1371/journal.pbio.1001705

315 R Development Core Team. (2016). R: A Language and Environment for Statistical Computing.

316 R Foundation for Statistical Computing Vienna Austria, 0, \{ISBN\} 3-900051-07-0.

$317 \quad$ http://doi.org/10.1038/sj.hdy.6800737

318 Rissing, S.W. (1986). Indirect effects of granivory by harvester ants: plant species

319 composition and reproductive increase near ant nests. Oecologia 68: 231.

320 https://doi.org/10.1007/BF00384792

321 Stuble, K. L., Andrew, N., Patterson, C. M., Rodriguez-Cabal, M. A., Ribbons, R. R., Dunn, R.

322 R., \& Sanders, N. J. (2014). Ant-mediated seed dispersal in a warmed world. PeerJ

323 http://doi.org/10.7717/peerj.286

324 Taber, S. W. (1999). The world of the harvester ants. Texas A \& M University Press.

325 Warren, R. J., \& Giladi, I. (2014). Ant-mediated seed dispersal: A few ant species

326 (Hymenoptera: Formicidae) benefit many plants. Myrmecological News. 
327 Warren, R. J., Elliott, K. J., Giladi, I., King, J. R. and Bradford, M. A. (2018), Field experiments

328 show contradictory short- and long-term myrmecochorous plant impacts on seed-dispersing 329 ants. Ecological Entomology. doi:10.1111/een.12666

330 Zelikova, T. J., Dunn, R. R., \& Sanders, N. J. (2008). Variation in seed dispersal along an

331 elevational gradient in Great Smoky Mountains National Park. Acta Oecologica, 34(2),

$332 \quad 155-162$. http://doi.org/10.1016/j.actao.2008.05.002 


\section{Figure legends}

335

336 Figure 1. Mean seed removal rates per seed depot along the elevation gradient over a 48-hour period. Squares $=1600$ m.a.s.1., circles $=2200$ m.a.s.1. and triangles $=2800$ m.a.s.1. Bars indicate standard error about means.

339

Figure 2. Mean species-specific seed removal rates per station along the elevation gradient over a 48-hour period. Squares=1600 m.a.s.l., circles $=2200$ m.a.s.1., triangles $=2800$ m.a.s.l. Bars indicate standard error about means.

344 Figure 3. Principal components analysis showing ant community composition grouped by 345 elevation band (triangles- high, circles- mid, squares- low) at the generic level with ellipses indicating 95\% confidence intervals for each elevation band (yellow- high, bluemid, green- low).

348

349

350

351

352

353

354

355

356 
Figure 1

Mean seed removal rates per bait station along the elevation gradient over a 48-hour period.

Squares $=1600$ m.a.s.I., circles $=2200$ m.a.s.l. and triangles $=2800$ m.a.s.l. Bars indicate standard error about means.

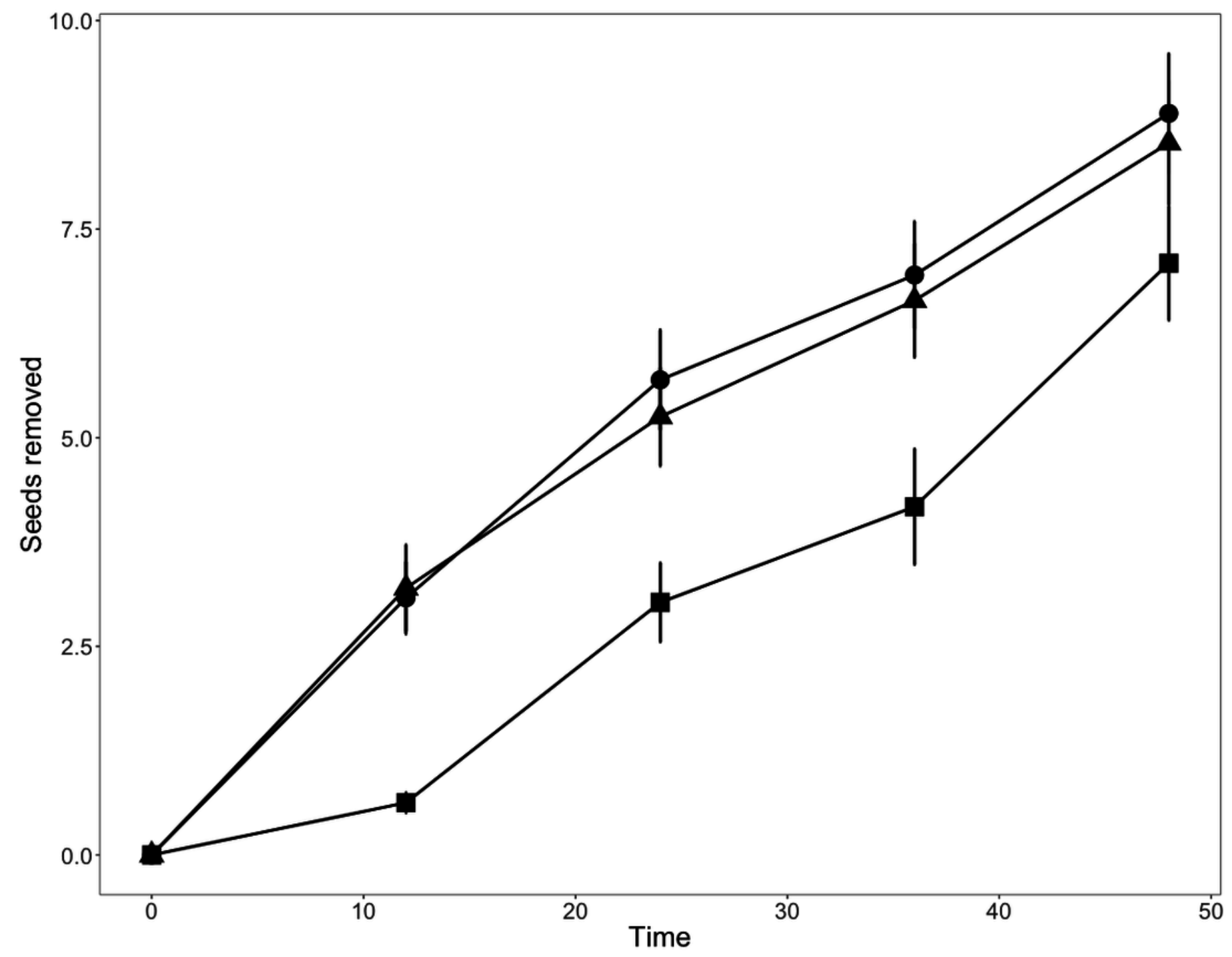


Figure 2

Mean species-specific seed removal rates per station along the elevation gradient over a 48-hour period.

Squares $=1600$ m.a.s.l., circles $=2200$ m.a.s.l., triangles $=2800$ m.a.s.l. Bars indicate standard error about means.
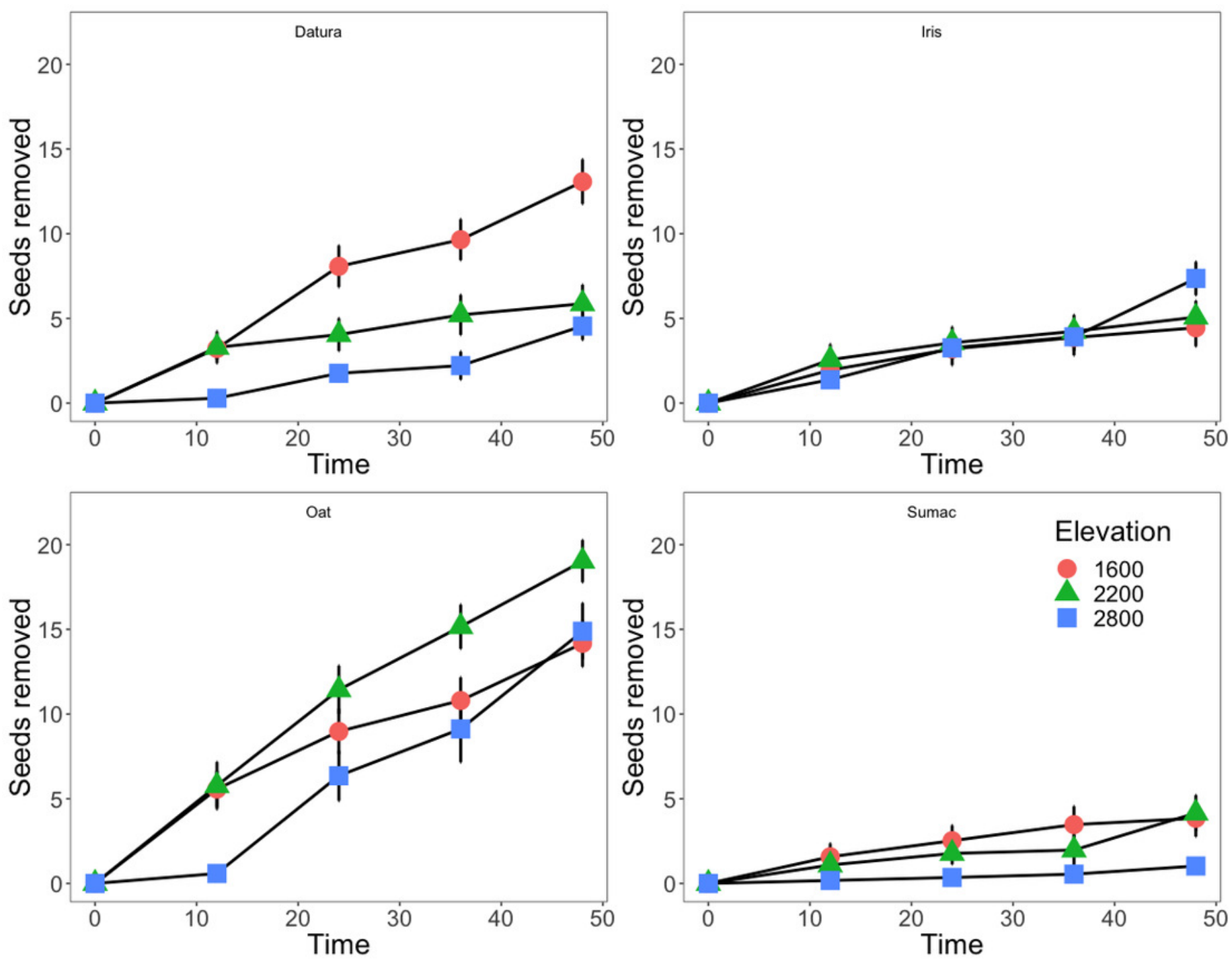
Figure 3

Principal components analysis of ant community composition.

Grouped by elevation band (triangles- high, circles- mid, squares- low) at the generic level with ellipses indicating $95 \%$ confidence intervals for each elevation band (yellow- high, bluemid, green- low).

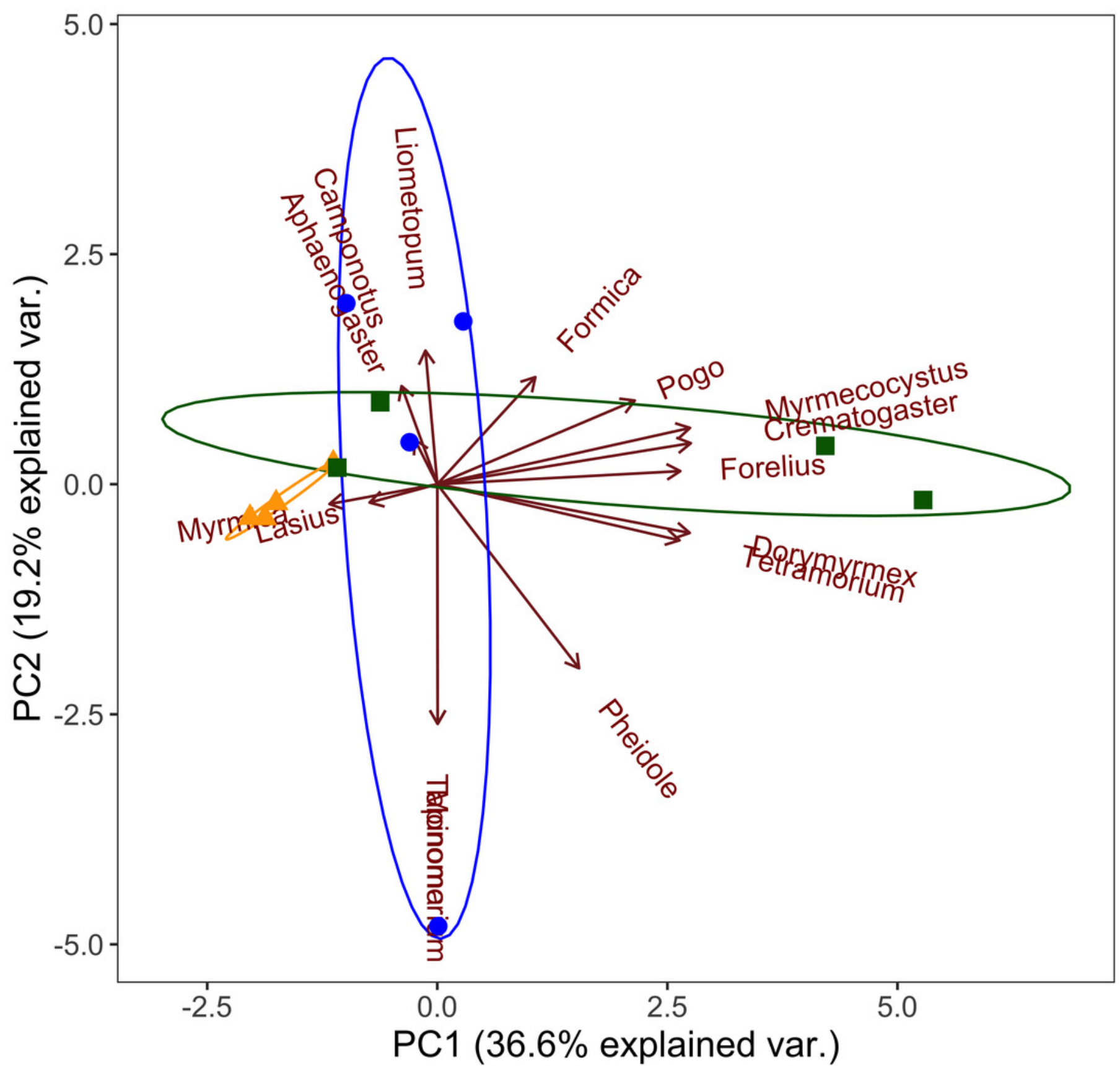




\section{Table 1 (on next page)}

Plant study species details and observed seed-dispersing ant genera. 
1 Table 1. Plant study species details and observed seed-dispersing ant genera:

\begin{tabular}{|l|l|l|l|}
\hline $\begin{array}{l}\text { Plant Common } \\
\text { Name }\end{array}$ & $\begin{array}{l}\text { Plant scientific } \\
\text { name }\end{array}$ & $\begin{array}{l}\text { Native elevation } \\
\text { range (m.a.s.1.) }\end{array}$ & $\begin{array}{l}\text { Observed seed-dispersers } \\
\text { (ant genera) }\end{array}$ \\
\hline Sacred Datura & Datura wrightii & $1200-1800$ & $\begin{array}{l}\text { Pogonomyrmex, } \\
\text { Novomessor }\end{array}$ \\
\hline Littleleaf Sumac & Rhus microphylla & $1800-2400$ & $\begin{array}{l}\text { Pogonomyrmex, } \\
\text { Novomessor, Pheidole }\end{array}$ \\
\hline $\begin{array}{l}\text { Rocky Mountain } \\
\text { Iris }\end{array}$ & Iris missouriensis & $2400-3200$ & Formica, Myrmica \\
\hline Common Oat & Avena sativa & $\begin{array}{l}\text { Middle east (non- } \\
\text { native control) }\end{array}$ & $\begin{array}{l}\text { Pogonomyrmex, } \\
\text { Novomessor, Liometopum }\end{array}$ \\
\hline
\end{tabular}

2 


\section{Table 2 (on next page)}

RMANOVA table of total seeds removed over time, partitioned by each seed species using Type II Wald Chi sq. tests. 
1 Table 2. RMANOVA table of total seeds removed over time, partitioned by each seed species 2 using Type II Wald Chi sq. tests.

3

\begin{tabular}{|llrr|}
\hline & Fixed effects & Chi sq & $\operatorname{Pr}(<$ Chi sq $)$ \\
\hline Global model & Hours & 690.722 & $<0.001$ \\
& Elevation: Seed & 560.986 & $<0.001$ \\
\hline Datura wrightii & Hours & 300.565 & $<0.001$ \\
& Elevation & 27.533 & $<0.001$ \\
& Site & 9.304 & 0.026 \\
\hline Iris missouriensis & Hours & 258.427 & $<0.001$ \\
& Elevation & 13.511 & 0.001 \\
& Site & 9.343 & 0.025 \\
\hline Avena sativa & Hours & 411.720 & $<0.001$ \\
& Elevation & 12.230 & 0.002 \\
& Site & 25.450 & $<0.001$ \\
\hline Rhus microphylla & Hours & 76.433 & $<0.001$ \\
& Elevation & 8.117 & 0.017 \\
& Site & 4.902 & 0.179 \\
\hline
\end{tabular}

4 